\title{
Baboon Lymphoma
}

National Cancer Institute

\section{Source}

National Cancer Institute. Baboon Lymphoma. NCI Thesaurus. Code C134766.

Lymphoma that occurs in a baboon. 